\title{
Przestrzenne zróżnicowanie wskaźników litologicznych i geochemicznych w obrębie reliktów domostwa na stanowisku archeologicznym kultury Vatya z epoki brązu w Kakucs-Turján (Węgry)
}

\author{
Spatial variability of the lithological and geochemical indicators within relics of the homestead \\ on the archaeological site of the Vatya culture from the Bronze Age in Kakucs-Turján (Hungary)
}

\author{
Joanna Galas ${ }^{1}$, Mateusz Jaeger ${ }^{2}$ \\ 'Instytut Geoekologii i Geoinformacji, Uniwersytet im. Adama Mickiewicza w Poznaniu; joanna.galas@amu.edu.pl \\ ${ }^{2}$ Instytut Kultury Europejskiej, Uniwersytet im. Adama Mickiewicza w Poznaniu
}

\begin{abstract}
Zarys treści: W artykule przedstawiono wyniki badań litologicznych i geochemicznych podłoża badanego wykopaliskowo fragmentu osady z epoki brązu ludności kultury Vatya, w Kakucs-Turján, Węgry. Wyniki badań dowodzą zróżnicowania przestrzennego cech litologicznych (wskaźników uziarnienia) i geochemicznych badanego obszaru. Jest ono efektem kierunków i intensywności użytkowania badanej strefy (zajmowanej przez obiekt mieszkalny) oraz oddziaływania procesów podepozycyjnych, szczególnie spłukiwania. W badaniach geochemicznych w niektórych częściach obiektu mieszkalnego potwierdzono ich intensywne użytkowanie gospodarcze. Największe nagromadzenie fosforu odnotowano na zewnątrz chaty, w pobliżu wejścia.
\end{abstract}

Słowa kluczowe: badania litologiczne i geochemiczne, stanowisko archeologiczne, obiekt mieszkalny, epoka brązu, Węgry

Abstract: The article presented the results of lithologic and geochemical investigations of the subsoil of a part of the Vatya culture settlement dating back to the bronze age, subject to excavations and located in Kakucs-Turján, Hungary. The results of the conducted research study showed spatial variability of lithologic (granulometric indices) and geochemical features of the investigated area. It was the result of directions and intensity of using the analysed area (occupied by a cottage) and the influence of post-depositional processes, especially ablation. The geochemical analysis confirmed intensive farm use of some parts of the cottage. The greatest phosphorus accumulation was found outside the hut, near the entrance.

Keywords: lithologic and geochemical investigations, archaeological site, cottage, the Bronze Age, Hungary

\section{Wprowadzenie}

Obecność miąższych pokryw lessowych oraz zachodzące $\mathrm{w}$ późnym holocenie zmiany klimatyczne sprzyjały intensywnemu rozwojowi osadnictwa epoki brązu w międzyrzeczu Dunaju i Cisy. Na żyznych terenach równinnych, w bliskiej odległości od cieków wodnych, pełniących często ważne funkcje komunikacyjne, w pierwszej połowie II tys. przed Chr. powstał szereg osad, w wielu przypadkach zasiedlanych nieprzerwanie przez kilka stuleci. Przykładem takiej osady jest stanowisko Kakucs-Turján, oddalone około $40 \mathrm{~km}$ na południowy wschód od dzisiejszego Budapesztu. Stanowisko to jest jednym z licznych (ponad 30 dotąd znanych) przykładów osad obronnych ludności kultury Vatya ulokowanych na obszarze środkowego dorzecza Dunaju (Jaeger 2016).

Mikroregion Kakucs, zlokalizowany w centralnej części współczesnych Węgier, obfituje w źródła związane $z$ kulturą Vatya, dominującą w środkowej epoce brązu w tej strefie. Obok licznych skarbów przedmiotów metalowych i znalezisk luźnych, do najistot- 
niejszych stanowisk w mikroregionie należy zaliczyć, często bardzo rozległe, cmentarzyska, z eponimicznym stanowiskiem Újhartyán-Vatya-puszta (Bóna, Meller 1975) oraz liczne osady otwarte i obronne (Szeverényi, Kulcsár 2012). Osady otwarte znane są przede wszystkim z wyników badań ratowniczych oraz prospekcji terenowych. Niewiele wiemy o ich wewnętrznej strukturze i typie zabudowy mieszkalnej. Podstawowymi źródłami archeologicznymi są liczne jamy gospodarcze. Grupę stanowisk umocnionych fortyfikacjami stanowią osady w: Dabas-Dabasi szőlők, Dabas-Sári/Bugyi, Soroksár-Várhegy, Dömsöd, Kakucs-Balla-Domb oraz Kakucs-Turján (ryc. 1).

Stanowiska te są aktualnie przedmiotem bardziej szczegółowych badań polsko-węgiersko-niemieckiego zespołu archeologów (Kakucs Archaeological Expedition - KEX). W ramach projektu rozpoznano nieinwazyjnie za pomocą magnetometrii oraz badań powierzchniowych trzy stanowiska (Dabas-Sári/Bugyi, Dömsöd, Kakucs-Turján), określając wstępnie ich pozycję chronologiczną i rozpoznając strukturę elementów zabudowy wewnętrznej oraz umocnień. Ponadto przeprowadzono reanalizę materiałów $\mathrm{z}$ badań archiwalnych w Kakucs-Balla-Domb, datując metodą radiowęglową serię 10 próbek z kości (Jaeger, Kulcsár 2013, Jaeger 2016). W ramach projektu badania skoncentrowane zostały jednak przede wszystkim na obszarze osady Kakucs-Turján. Od 2013 r. przeprowadzone zostały: prospekcja magnetometryczna, badania wykopaliskowe oraz kartowania geologicz-

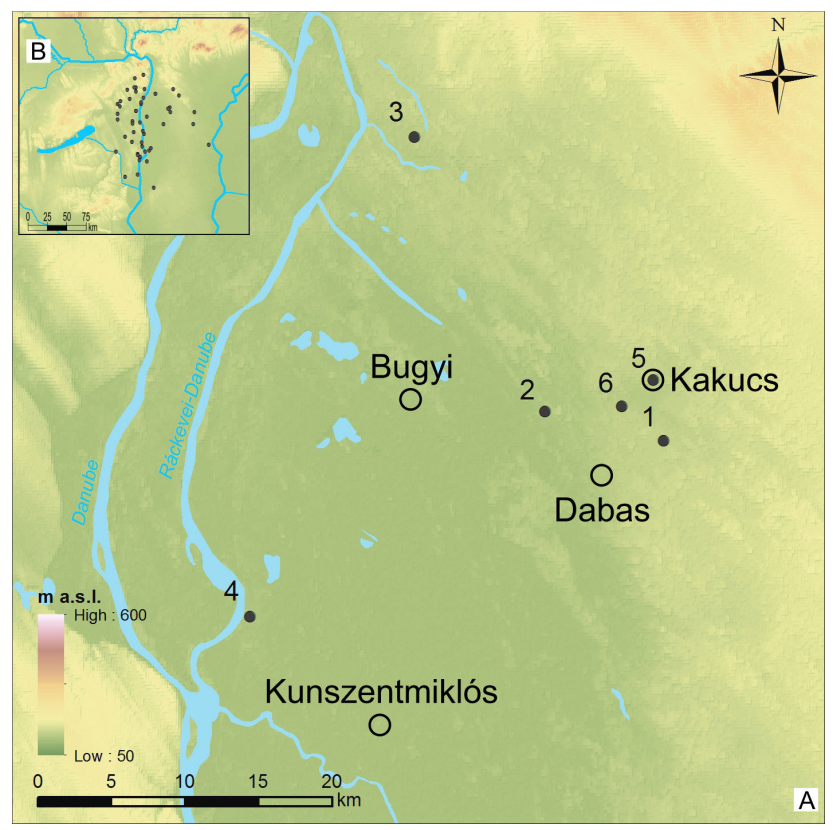

Ryc. 1. Lokalizacja osad obronnych w mikroregionie Kakucs (A) na tle ogólnego rozprzestrzenienia stanowisk wielowarstwowych oraz tellowych kultury Vatya (B)

Fig. 1. Location of defensive settlements in Kakucs microregion (A) compared to general distribution of multilayer and tell sites of the Vatya culture (B) ne i analizy specjalistyczne z zakresu archeozoologii oraz archeobotaniki.

Głównym celem przedstawionego opracowania jest weryfikacja hipotetycznego podziału funkcjonalnego osady uzyskanego $\mathrm{w}$ wyniku badań magnetometrycznych. Jej podstawą była analiza przestrzennego zróżnicowania cech litologicznych i geochemicznych osadów z poziomów podhumusowych, stanowiących górne partie nawarstwień kulturowych, w których odkryto pozostałości chaty.

Wyniki analiz teksturalnych, zawartości $\mathrm{CaCO}_{3}$ oraz materii organicznej porównano $z$ wynikami badań magnetometrycznych, co pozwoliło na potwierdzenie zróżnicowania funkcjonalnego badanej wykopaliskowo części osady, w obrębie pozostałości chaty oraz jej najbliższego otoczenia.

\section{Osada obronna w Kakucs-Turján}

Osada w Kakucs-Turján jest jednym z sześciu stanowisk obronnych zlokalizowanych na relatywnie niewielkiej przestrzeni mikroregionu Kakucs. Osada została zidentyfikowana $\mathrm{w}$ wyniku rekonesansu lotniczego przez archeologów węgierskich Z. Czajlika i Z. Miklósa. Wskaźniki wegetacyjne ukazywały charakterystyczną dwudzielną strukturę osady. Przeprowadzone $\mathrm{w}$ ramach projektu badania magnetometryczne ujawniły bardziej złożony układ przestrzenny stanowiska (ryc. 2). Obszar stanowiska podzielony

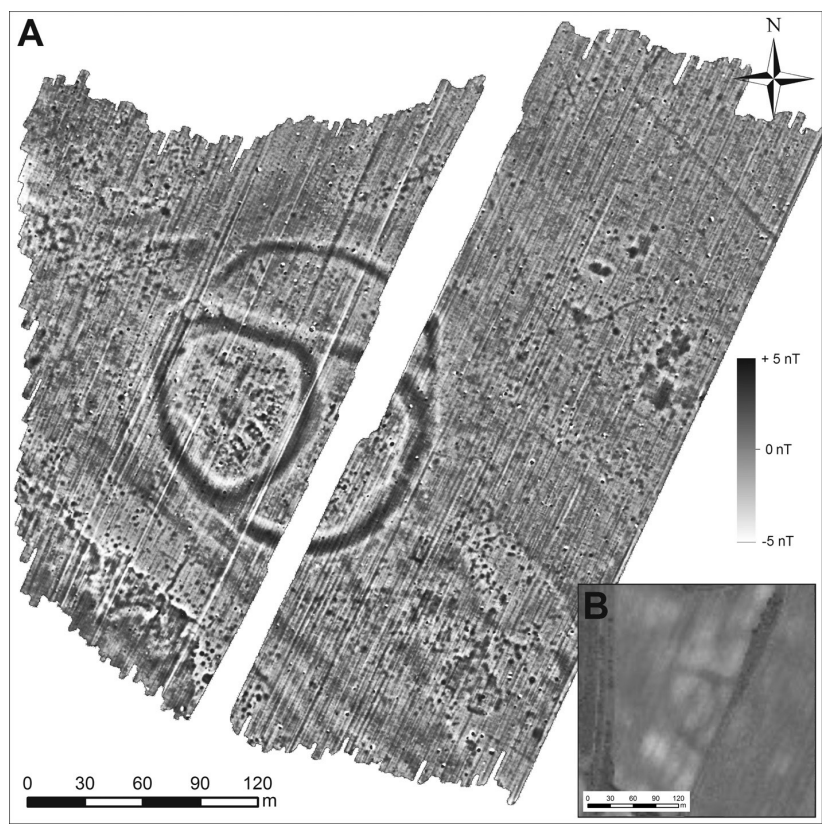

Ryc. 2. Stanowisko archeologiczne Kakucs-Turján; A - na obrazie geomagnetycznym, B - na zdjęciu satelitarnym

Fig. 2. Kakucs-Turján archaeological site; A - on a geomagnetic map, B - on a satellite map 
był na trzy części. Tylko w obrębie jednej z nich zarejestrowano anomalie magnetyczne identyfikowane jako pozostałości zabudowy. W kolejnej części osady widoczne są anomalie, które prawdopodobnie interpretować należy jako ślady działalności gospodarczej, związane przede wszystkim z obecnością jam zasobowych. Trzecia część stanowiska dostarczyła relatywnie niewielkiej ilości anomalii i wstępnie jej funkcja określona została jako przestrzeń przetrzymywania zwierząt hodowlanych. Fortyfikacje, których relikty uwidocznione są na mapie anomalii magnetycznych oraz częściowo na zdjęciach satelitarnych, tworzyły głębokie (do $3 \mathrm{~m}$ ) i szerokie (do $12 \mathrm{~m}$ ) fosy, dzielące teren osady na trzy części.

W świetle aktualnych wyników badań wykopaliskowych stwierdzić można, że obszar stanowiska w Kakucs-Turján zasiedlony został po raz pierwszy w sposób stały we wczesnej epoce brązu (wg terminologii węgierskiej), tj. na przełomie III i II tys. przed Chr. Pozostałością tej fazy osadniczej są liczne, bardzo głębokie (do 1,50 m) jamy zasobowe, odkryte w najniższych poziomach stratygraficznych obu eksplorowanych wykopów. Z tych obiektów archeologicznych pozyskano materiał charakterystyczny dla kultury Nagyrév. Kolejny i zarazem główny etap zasiedlenia stanowiska wiąże się z powstaniem umocnionej osady kultury Vatya. Okres jej funkcjonowania, w świetle typochronologii zabytków, określić można wstępnie na około 2000/1900 do 1500/1450 lat przed Chr. Zabudowę mieszkalną osady stanowiły relatywnie duże, $w$ przybliżeniu prostokątne budynki, o glinianych ścianach opartych o lekką drewnianą konstrukcję. Sekwencję stratygraficzną na stanowisku zamyka warstwa kulturowa będąca pozostałością użytkowania terenu osady w okresie Koszider (schyłek środkowej epoki brązu; przełom pierwszej i drugiej połowy II tys. przed Chr.).

Wyniki dotychczasowych badań pozwoliły udokumentować szereg źródeł poświadczających rozwiniętą gospodarkę rolno-hodowlaną mieszkańców osady, a także ich udział w złożonej interregionalnej wymianie surowców niedostępnych lokalnie, takich jak: brąz, złoto oraz obsydian. Również w bardzo licznym zbiorze fragmentów ceramiki widoczny jest wyraźny udział wzorców stylistycznych (imitacji oraz właściwych importów naczyń) pochodzących z ościennych regionów kulturowo-geograficznych.

\section{Charakterystyka obszaru badań}

Cechą charakterystyczną budowy geologicznej znacznego obszaru Węgier jest położenie w zapadlisku tektonicznym. Lokalizacja w środkowoeuropejskiej strefie młodych gór Eurazji (Karpaty, Alpy i Góry Dynarskie) znacząco wpływa na uwarunkowania klimatyczne,

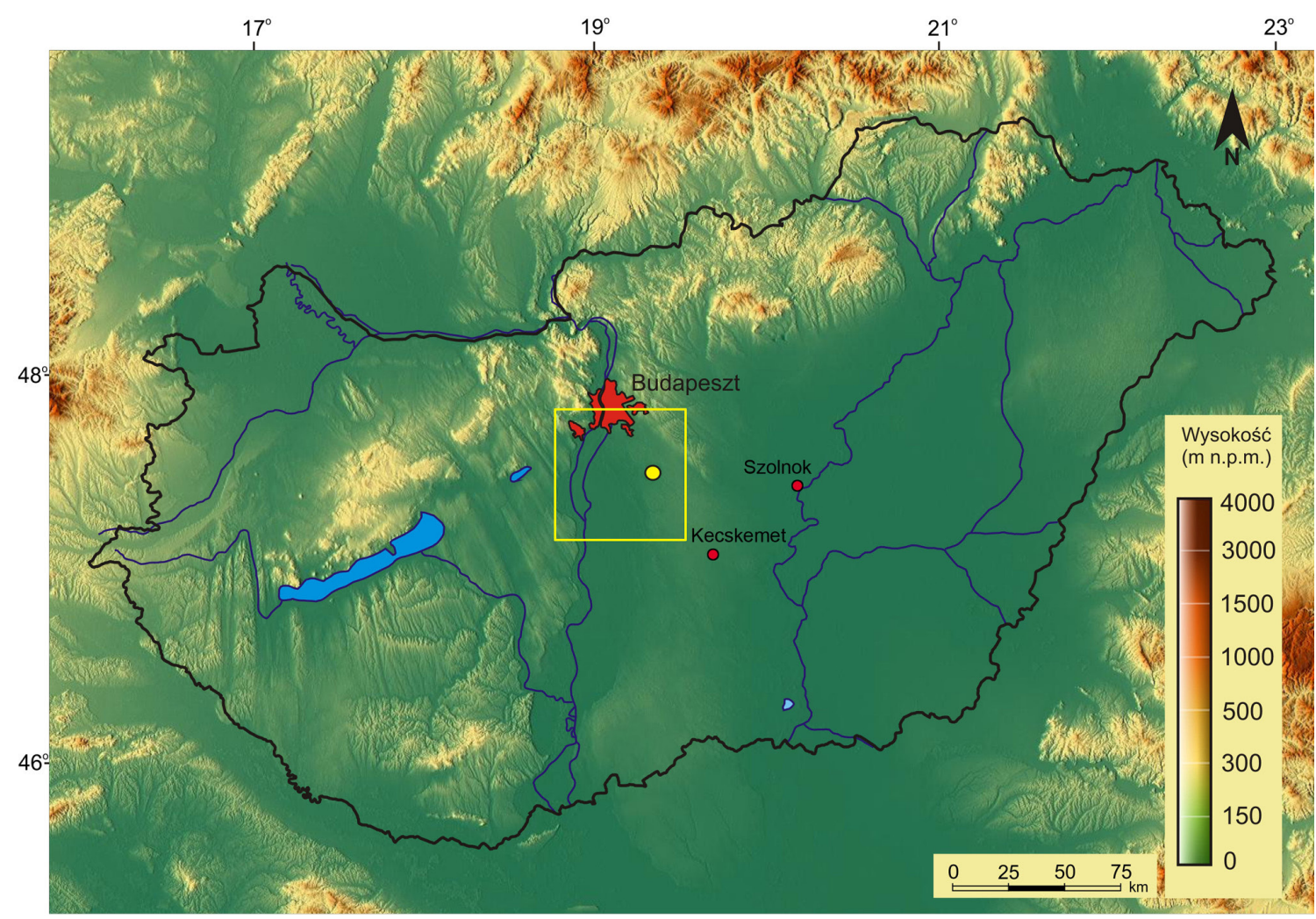

Ryc. 3. Lokalizacja obszaru (żółta kropka) na tle ukształtowania terenu (opracowanie na podstawie danych elevation.maplogs. com)

Fig. 3. Location of the area (yellow dot) compared to natural topography (on the basis of data from elevation.maplogs.com) 


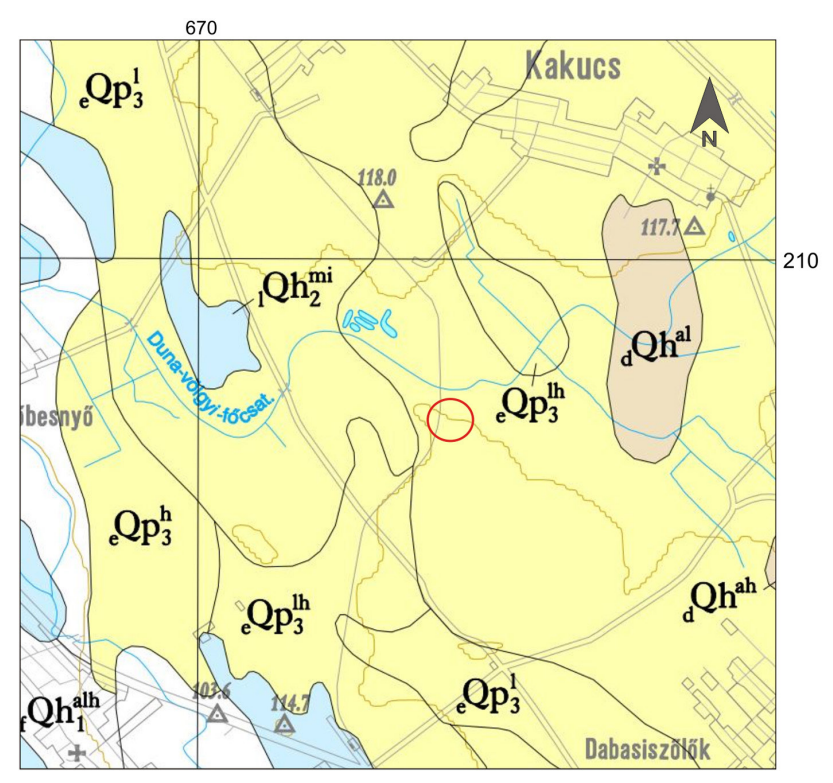

\begin{tabular}{llllllll}
1 & 0 & 1 & 2 & 3 & 4 & $5 \mathrm{~km}$ \\
\hline
\end{tabular}

Ryc. 4. Mapa geologiczna utworów powierzchniowych w otoczeniu stanowiska archeologicznego, arkusz Dabas, L-34-27, Geological and Geophysical Institute of Hungary/Magyrar Foldtani es Geofizikai Intezet (Kuti 2005) ${ }_{\mathrm{e}} \mathrm{Qp}_{3}{ }_{3}$ - lessy plejstoceńskie, $\mathrm{eQp}_{3}{ }_{3}$ - lessy plejstoceńskie spiaszczone, ${ }_{\mathrm{e}} \mathrm{Qp}^{\mathrm{h}}{ }_{3}$ - piaski plejstoceńskie, ${ }_{1} \mathrm{Qh}^{\mathrm{mi}}{ }_{2}$ - osady węglanowe zagłębień bezodpływowych, $\mathrm{Qh}^{\text {alh }}{ }_{1}$ - piaski aleurytowe holoceńskie fluwialne, ${ }_{d} \mathrm{Qh}^{\text {al }}$ - deluwia aleurytowe, ${ }_{\mathrm{d}} \mathrm{Qh}^{\text {ah }}$ - glina piaszczysta deluwialna

Fig. 4. Geologic map of surface sediments within the surroundings of the archaeological site, Dabas sheet, L-3427, Geological and Geophysical Institute of Hungary/ Magyrar Foldtani es Geofizikai Intezet (Kuti 2005)

${ }_{\mathrm{e}} \mathrm{Qp}_{3}^{1}$ - Pleistocene loess, $\mathrm{eQp}_{3}{ }_{3}$ - sandy Pleistocene loess, ${ }_{\mathrm{e}} \mathrm{Qp}^{\mathrm{h}}{ }_{3}$ - Pleistocene sands, ${ }_{1} \mathrm{Qh}^{\mathrm{mi}}{ }_{2}$ - carbonate sediments of closed depressions, $\mathrm{Qh}_{\mathrm{alh}}{ }_{1}$ - Holocene fluvial aleurite sand, ${ }_{\mathrm{d}} \mathrm{Qh}^{\text {al }}$ - aleurite colluvium, ${ }_{\mathrm{d}} \mathrm{Qh}^{\text {ah }}-$ colluvial sandy clay

geomorfologiczne, hydrologiczne oraz botaniczne wnętrza kraju (Kocsis, Schweitzer 2009) (ryc. 3).

Stanowisko archeologiczne Kakucs-Turján leży na obszarze zajętym przez plejstoceńskie i holoceńskie osady pylasto-piaszczyste o genezie głównie eolicznej oraz częściowo fluwialnej (Smalley, Leach 1978, Kis 1995) (ryc. 4). Analizowany teren, w dużej mierze równinny, pokrywają urodzajne gleby, takie jak czarnoziemy, gleby aluwialne, gleby o genezie eolicznej, bardziej piaszczyste oraz gleby bagienne. W sąsiedztwie stanowiska, od strony północnej przepływa rzeka Duna-völgyi-Főcsatorna, będąca jednym $z$ dopływów Dunaju, o średniej szerokości koryta 8-10 m i głębokości nieprzekraczającej $4 \mathrm{~m}$ (ryc. 5).

Analiza warunków hipsometrycznych wskazuje, że osada położona jest na wysokości 108-111 m n.p.m., na prawie płaskiej powierzchni o lekkim nachyleniu w kierunku północnym. Z analizy ukształtowania terenu wynika również, że usytuowanie osa-

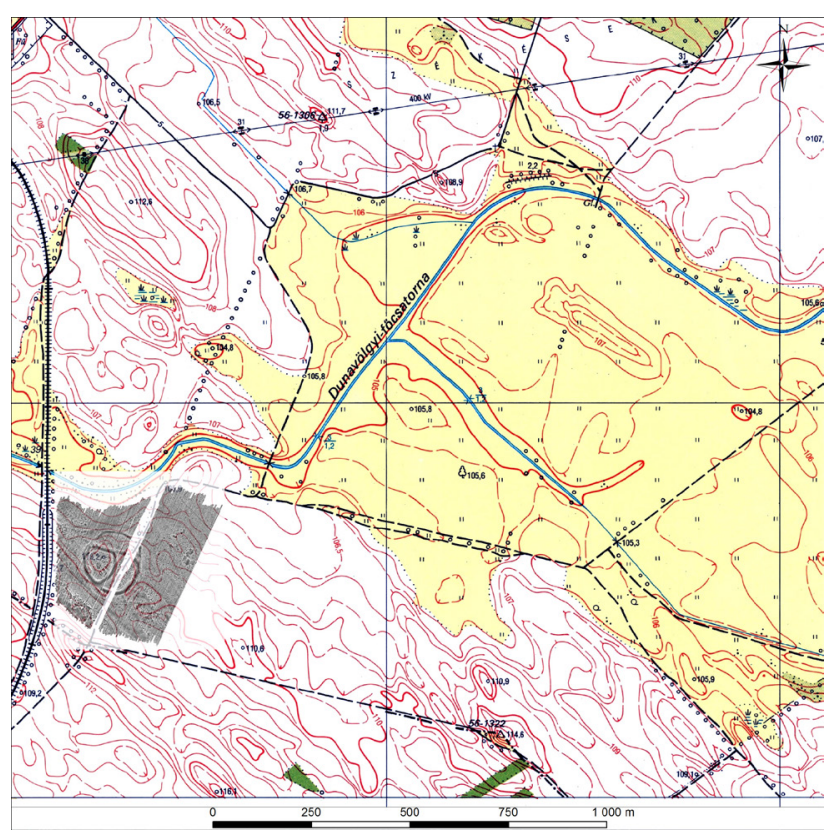

Ryc. 5. Lokalizacja stanowiska archeologicznego Kakucs-Turján na tle mapy topograficznej. Żółty kolor oznacza łąki i pastwiska

Fig. 5. Location of Kakucs-Turján archaeological site compared to the topographic map. Meadows and pastures are marked in yellow

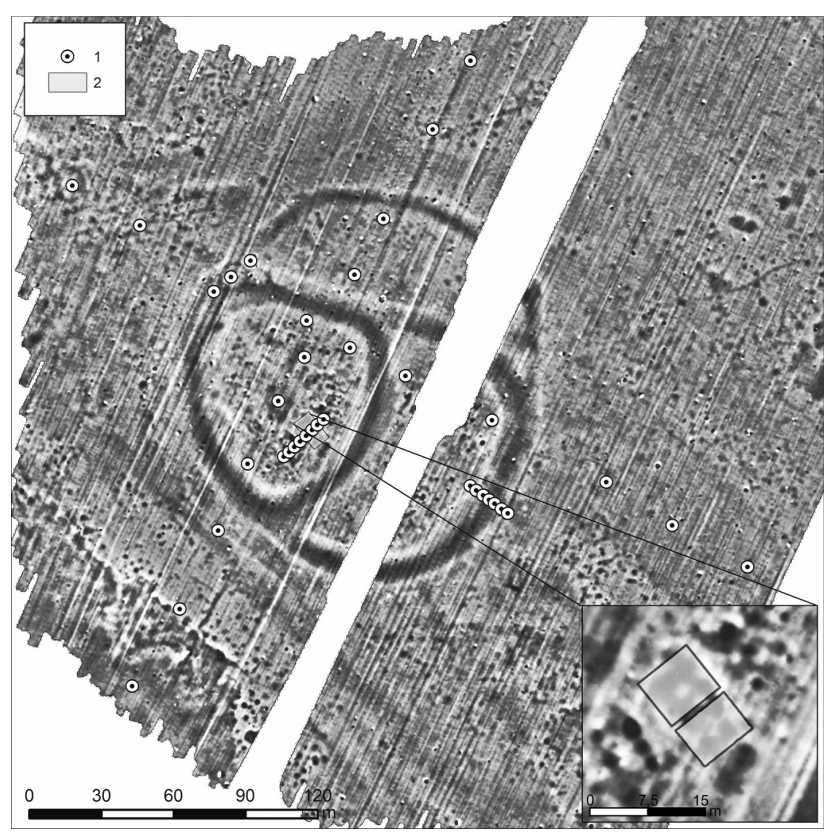

Ryc. 6. Mapa anomalii magnetycznych stanowiska archeologicznego Kakucs-Turján; 1 - lokalizacja odwiertów, 2 - lokalizacja wykopów archeologicznych

Fig. 6. Map of magnetic anomalies of Kakucs-Turján archaeological site; 1 - location of bore holes, 2 - location of archaeological trenches

dy w tym miejscu oraz budowa umocnień, a także wykopanie fos, spowodowały przekształcenie morfometrii tego terenu i powstanie trójdzielnej struktury osady (ryc. 6). 


\section{Metody}

W zachodniej części stanowiska archeologicznego, w której prospekcja geomagnetyczna udokumentowała relikty pozostałości obiektów mieszkalnych o prostokątnych zarysach (ryc. 7), przeprowadzone zostały weryfikacyjne badania wykopaliskowe wybranego obiektu. Odkryto pozostałości ścian oraz podłogi chaty, a także pieca o średnicy około $100 \mathrm{~cm}$.

Wykop archeologiczny (oznaczony nr 1) miał wymiary $8 \times 7$ m (ryc. 8). Pobrano z niego 248 próbek osadów powierzchniowych pochodzących $z$ poziomu podhumusowego i warstwy mechanicznej, która jest warstwą kulturową stanowiska archeologicznego. Następnie zostały one poddane analizom teksturalnym oraz geochemicznym (ryc. 9). Po wysuszeniu próbek w suszarce laboratoryjnej przesiano je wstępnie przez sito $2000 \mu \mathrm{m}$. Potem przeprowadzono analizę uziarnienia metodą dyfrakcjometrii laserowej, która pozwoliła określić w poszczególnych próbach wielkość i udział cząstek w zakresie frakcji od 0,2 do $2000 \mu \mathrm{m}$. W tym celu posłużono się analizatorem firmy Malvern Instruments: Malvernsize 2000 HydroG z przystawką wodną, który wykorzystuje zjawisko dyfrakcji wiązki światła, przechodzącej przez zawiesinę. Pozyskany w ten sposób pomiar rozkładu wskaźników posłużył do obliczenia podstawowych wskaźników uziarnienia metodą Folka i Warda (1957): mediany $(M z)$, odchylenia standardowego $(S D)$, skośności $\left(S_{k}\right)$ oraz kurtozy $\left(K_{G}\right)$. Wskaźniki uziarnienia obliczono w programie Gradistat 5.11 beta (Juśkiewicz 2006).

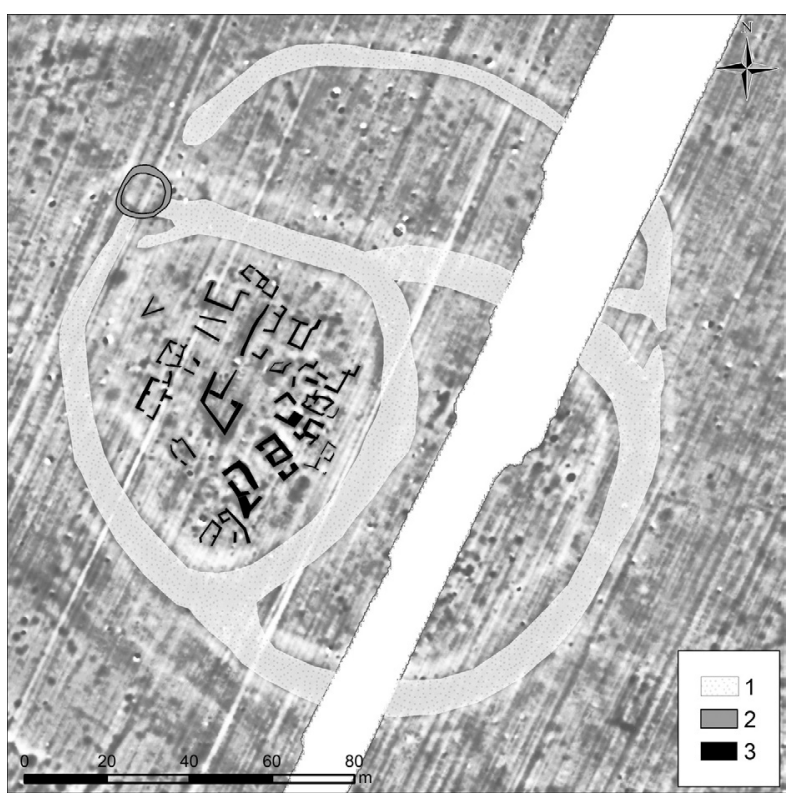

Ryc. 7. Interpretacja obrazu anomalii magnetycznych (weryfikowana wykopaliskowo oraz za pomocą odwiertów); 1 - przebieg fos, 2 - obiekty o charakterze studni, 3 - relikty zabudowy

Fig. 7. Interpretation of magnetic anomalies pictures (verified by excavation and drilled); 1 - course of the moat, 2 - objects of wells character, 3 - relics of cottages

Dalszym etapem prac laboratoryjnych było określenie zawartości materii organicznej i węglanu wapnia metodą strat prażenia. Procentową zawartość materii organicznej uzyskano poprzez obliczenie różnicy wagowej suchej próbki w stosunku do prób-

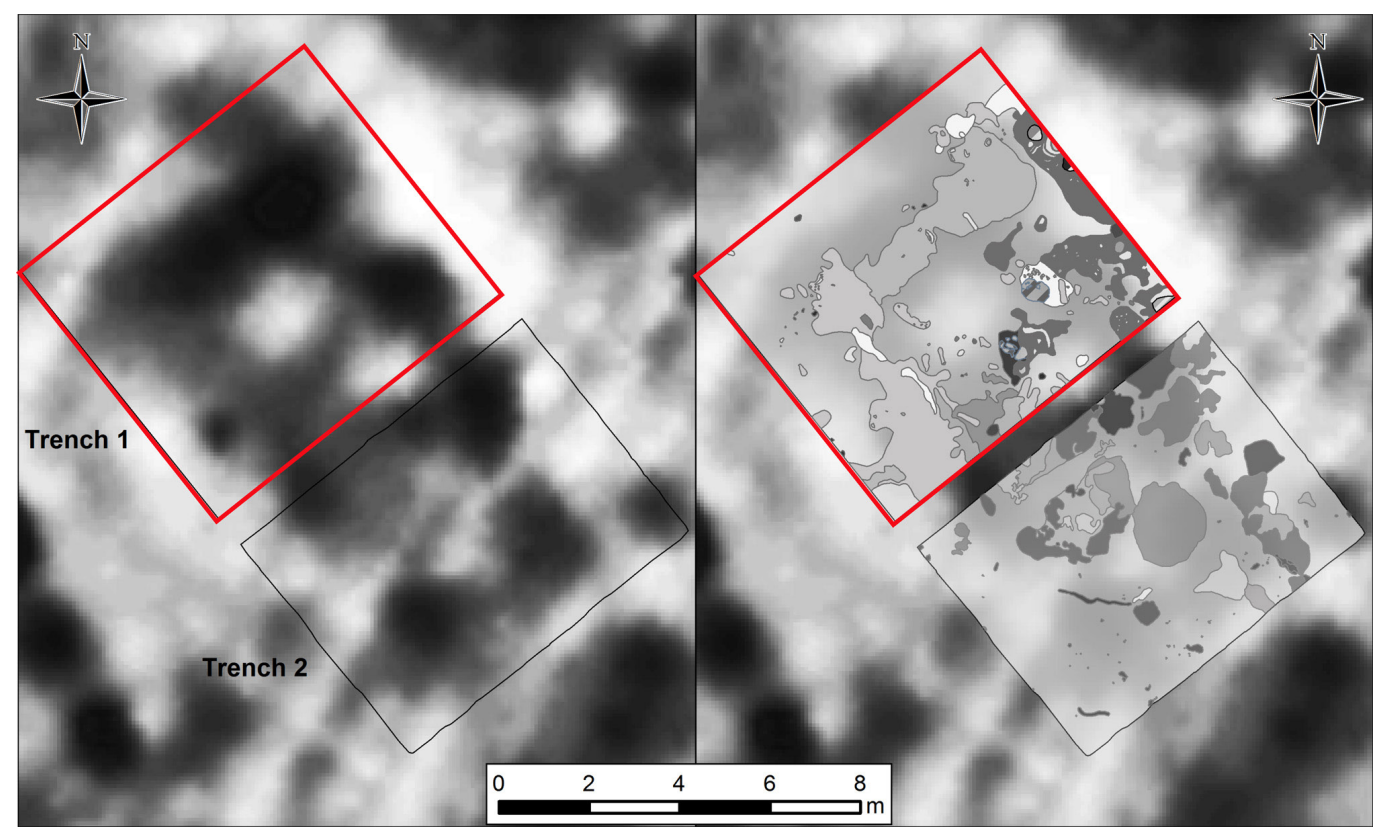

Ryc. 8. Zestawienie wyników prospekcji magnetometrycznej oraz odkrytych nawarstwień kulturowych w obrębie badanych wykopaliskowo reliktów chaty. Kolorem czerwonym oznaczono wykop nr 1

Fig. 8. List of magnetometric prospection results and exposed cultural strata within hut relics subject to excavations. The red color marked the trench 1 


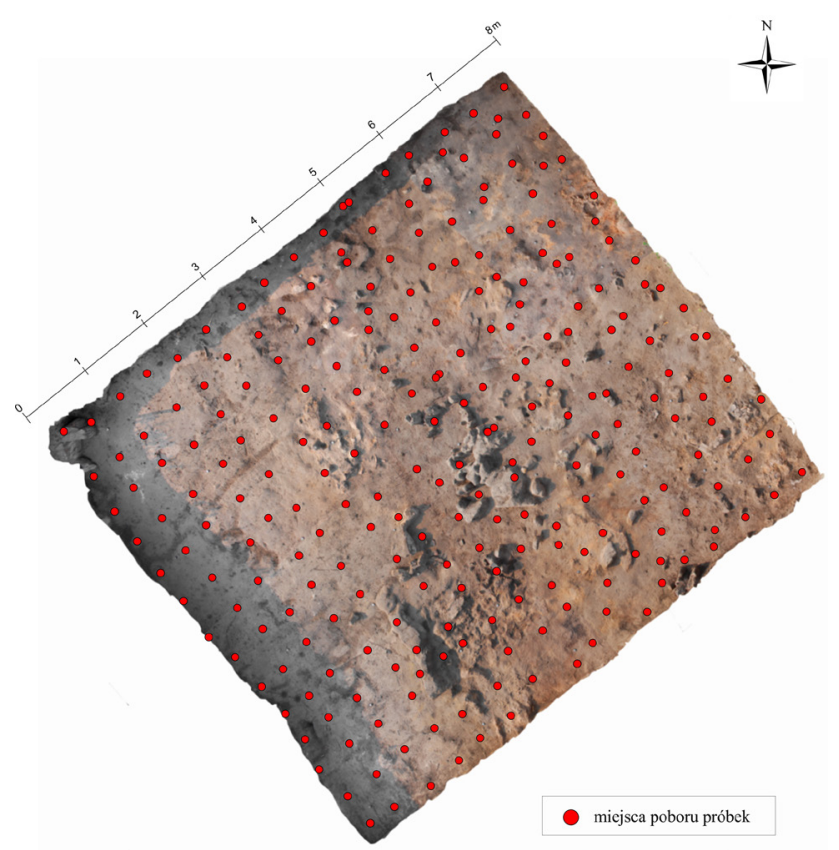

Ryc. 9. Rozmieszczenie punktów poboru próbek do analiz teksturalnych i geochemicznych

Fig. 9. Distribution of sampling points used for textural and geochemical analyses

ki wyprażonej w temperaturze $550^{\circ} \mathrm{C}$ przez okres 6 godzin, natomiast węglan wapnia $\mathrm{w}$ temperaturze $950^{\circ} \mathrm{C}$ przez 2 godziny (Heiri i in. 2001).

Wszystkie opisywane analizy wykonano w laboratorium sedymentologicznym i geochemicznym Zakładu Geologii i Paleogeografii Czwartorzędu WNGiG UAM. Dodatkowo w analizowanych próbach określono zawartość fosforu w Katedrze Gleboznawstwa Uniwersytetu Przyrodniczego w Poznaniu. Do oznaczania tego pierwiastka zastosowano metodę kolorymetryczną z molibdenianem amonu (Murphy, Riley 1962, Spychalski i in. 2016).

\section{Wyniki i dyskusja}

\section{Analiza cech litologicznych osadów powierzchniowych z wykopu archeologicznego}

Zestawienia udziału procentowego poszczególnych frakcji wskazują, że w analizowanych próbach występują osady pylaste oraz osady piaszczyste (ryc. 10). Dominują osady pylaste, są to pyły piaszczyste i pyły, których zawartość frakcji pyłowej waha się w granicach od 74 do 94,2\%. Udział frakcji piaszczystej jest zdecydowanie mniejszy i stanowi od 5,8 do 25,7\%. Otrzymane wartości pokazują, że badany osad jest stosunkowo jednorodny. Analizy uziarnienia potwierdziły eoliczny, lessowy charakter utworów powierzchniowych budujących podłoże stanowiska ar- cheologicznego. Są to typowe osady eoliczne pylaste transportowane na dalekim przedpolu lądolodu lub redeponowane, przewiewane osady dolin rzecznych dobrze udokumentowane na obszarze Węgier (Kis 1995). Osady te podlegały późniejszym przekształceniom w wyniku osadnictwa kultury Kakucs-Turján.

Za pomocą podstawowych wskaźników uziarnienia obliczonych metodą Folka i Warda (1957) wyznaczono: przeciętną wielkość ziaren $(M z)$, odchylenie standardowe $(S D)$, skośność $\left(S_{k}\right)$ i spłaszczenie $\left(K_{G}\right)$, na podstawie których dokonano charakterystyki litologicznej osadów (tab. 1).

Tabela 1. Wartości wskaźników uziarnienia

Table 1. The values of grain-size composition indicies

\begin{tabular}{lcccc}
\hline \multirow{2}{*}{ Parametr } & $M z$ & $S D$ & $S_{k}$ & $K_{G}$ \\
\cline { 2 - 5 } & \multicolumn{4}{c}{$[$ Phi] } \\
\hline Min. & 5,16 & 1,48 & 0,06 & 0,92 \\
Średnia & 5,69 & 1,70 & 0,03 & 1,14 \\
Maks. & 6,13 & 1,93 & 0,24 & 1,58 \\
\hline
\end{tabular}

Pierwszym analizowanym parametrem była przeciętna wielkość ziaren $(M z)$. Jest ona wskaźnikiem dynamiki środowiska sedymentacyjnego. Mimo że analizowane próbki osadów powierzchniowych charakteryzują się niewielkim zróżnicowaniem frakcjonalnym, to można na podstawie tego wskaźnika zaobserwować pewne zróżnicowanie ich rozkładu przestrzennego (ryc. 11). W niektórych strefach, interpretowanych jako obejścia chaty, czyli szlaki komunikacyjne, występuje nieco grubszy materiał. Prawidłowość tę zaobserwować można szczególnie w strefie zachodniej wykopu, wokół ścian chaty, gdzie odnotowano wzrost wielkości ziaren, który może świadczyć o nanoszeniu materiału o nieco grubszej frakcji, czyli utwardzaniu szlaku komunikacyjnego w trakcie użytkowania. Całość tej części, charakteryzującej się odmiennością rozkładu wskaźników uziarnienia, leży na zewnątrz ścian chaty, co może potwierdzać odmienność warunków depozycyjnych w trakcie użytkowania osady. Inną przyczyną zwiększenia wielkości ziaren w tej strefie może być położenie ścieżki w obniżeniu powstałym poprzez użytkowanie, co skupiało przepływ wody deszczowej i naturalną selekcję materiału, poprzez wynoszenie drobniejszego materiału.

Analizując przestrzenny rozkład wartości drugiego wskaźnika, czyli odchylenia standardowego (SD), zauważyć można wyraźną dominację osadów o słabym wysortowaniu (ryc. 11). Wartości wskaźnika SD mieszczą się w przedziale od 1,48 do 1,93 phi. Nieco lepsze wysortowanie odpowiada próbkom zlokalizowanym w strefie centralnej części wykopu odpowiadającej wnętrzu udokumentowanej chaty. Również próbki z części północno-wschodniej oraz wschodniej badanego obszaru wykazują nieco lepsze wysortowanie $\mathrm{w}$ porównaniu z pozostałymi jego fragmentami. 

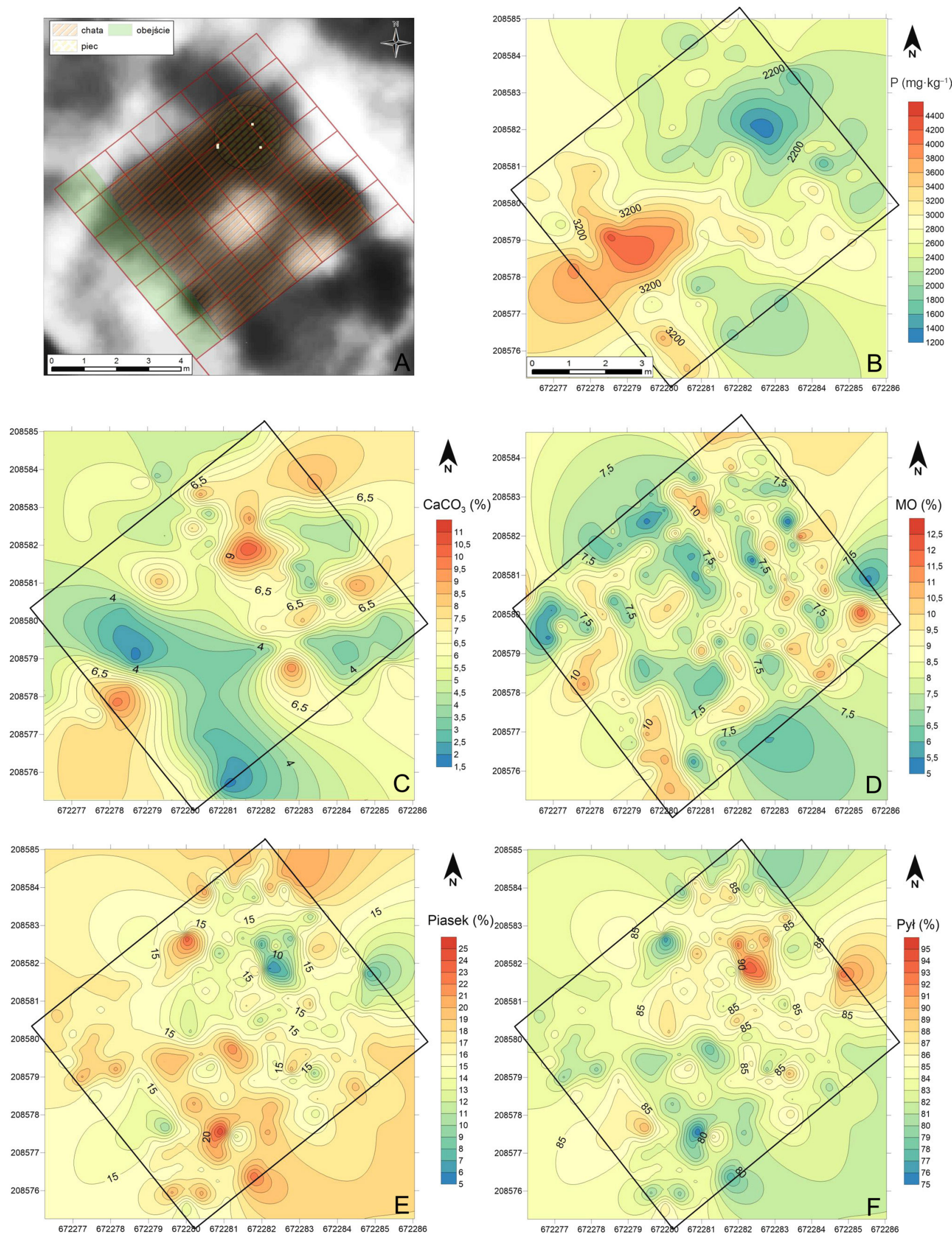

Ryc. 10. Podział funkcjonalny badanej wykopaliskowo części stanowiska (A) oraz przestrzenna zmienność cech geochemicznych i teksturalnych (\%): B - fosfor, C - węglan wapnia, D - materia organiczna, E - frakcja piaszczysta, F - frakcja pylasta Fig. 10. Functional division of the part of the site subject to excavations (A) and spatial variability of geochemical and textural features (\%): B - phosphorus, $\mathrm{C}$ - calcium carbonate, D - organic matter, $\mathrm{E}$ - sand fraction, $\mathrm{F}$ - clay fraction 
Przestrzenna zmienność wskaźników skośności $\left(S_{k}\right)$ dla badanych osadów charakteryzuje się zróżnicowaniem od wartości około zera do wartości dodatnich (ryc. 11). Taka rozbieżność świadczy o pewnej zmienności dynamiki środowiska sedymentacyjnego, w której akumulowany był materiał (Racinowski i in. 2001). Na jej rozkład przestrzenny wpływ ma naturalna zmienność osadów piaszczysto-pylastych, ale zaobserwowano pewne prawidłowości, które mogą wynikać z osadniczego wykorzystania tego obszaru w pradziejach. Najniższe wartości wskaźnika skośności odnotowano głównie w północnej i zachodniej części badanego obszaru. Wskazują one na występowanie w tych strefach domieszek frakcji grubszych. Wewnątrz chaty odnotowano dodatnią skośność, co świadczy o domieszkach drobniejszych frakcji. W tej
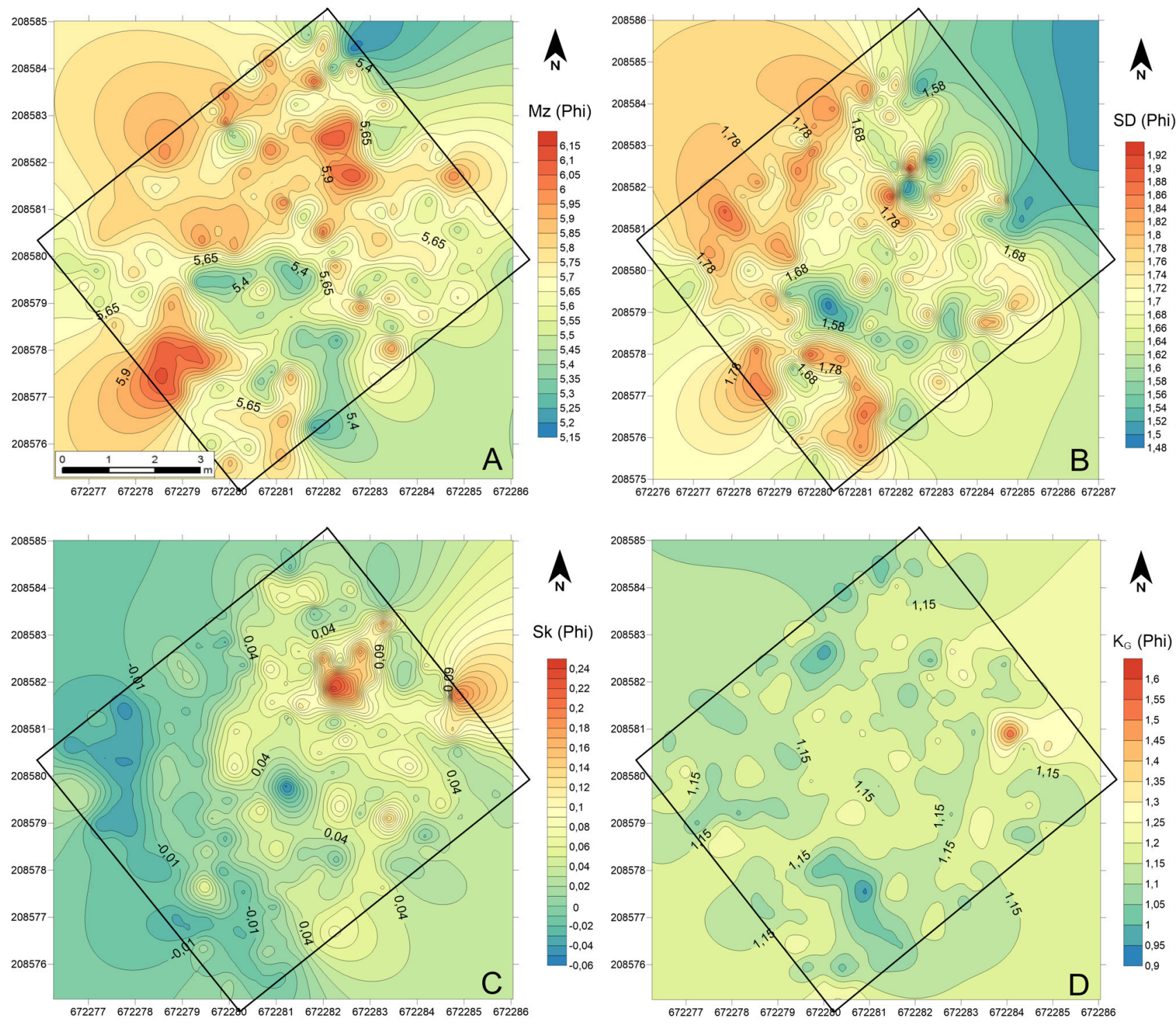

Ryc. 11. Przestrzenna zmienność parametrów uziarnienia (w skali Phi): A - średnia średnica ziarna, B - odchylenie standardowe, C - skośność, D - kurtoza

Fig. 11. Spatial variability of graining parameters (according to Phi scale): A - mean diameter of the grain, B - standard deviation, C - skewness, D - kurtosis 
ściach kurtozy. W centrum, w północno-wschodniej oraz wschodniej części dominują osady leptokurtyczne wskazujące na monofrakcyjność rozkładu uziarnienia. Osady mezokurtyczne odpowiadają próbkom zlokalizowanym w północnej i północno-zachodniej części stanowiska, czyli strefie o większej odrębności litologicznej.

Zawartość materii organicznej w badanych osadach mieści się $\mathrm{w}$ przedziale od 4,5 do około 12,5\% (tab. 2, ryc. 10). Na obecnym etapie badań, przy trwających jeszcze analizach makroszczątków roślinnych, trudno jednoznacznie stwierdzić, czy jej obecność związana jest z działalnością człowieka, czy z naturalnymi procesami zachodzącymi na badanym obszarze. Osady o wartościach materii organicznej powyżej 9,8\% zlokalizowane są głównie wzdłuż zachodniej i wschodniej granicy terenu badań oraz generalnie w części wschodniej. Punkty o średniej wartości wystąpiły głównie w części północnej, wschodniej oraz południowo-zachodniej. Najmniejszymi wartościami materii organicznej cechują się obszary centralny oraz północno-zachodni. Obecność najwyższych wartości materii organicznej w strefie północno-wschodniej można powiązać $z$ odkrytymi w kolejnych warstwach mechanicznych wyraźnymi pozostałościami pieca, wokół którego odnotowano liczne przepalone ziarna, a które nie zaznaczały się makroskopowo w badanej warstwie.

\section{Analiza cech geochemicznych osadów powierzchniowych z wykopu archeologicznego}

Ogólna koncentracja węglanu wapnia na badanym obszarze stanowiska Kakucs-Turján nie jest wysoka, jednak zauważalne jest jej zróżnicowanie przestrzenne. Rozmieszczenie przestrzenne węglanu wapnia nawiązuje do stref użytkowania obszaru (ryc. 10). Najniższa jego zawartość występuje w części zachodniej, aż po południowo-zachodni kraniec, gdzie przebiega obejście wokół chaty, którym mogły spływać wody opadowe, wynosząc drobniejszy materiał, co stwierdzono wcześniej, ale także ługując węglan wapnia. Średnie i wysokie wartości odnotowano na obszarze wnętrza chaty, w osadach w niej akumulowanych podczas użytkowania. W rozkładzie przestrzennym $\mathrm{CaCO}_{3}$ zauważyć można wzrost zawartości tego składnika w miejscu lokalizacji pieca. Źródłem węglanu wapnia w obrębie chaty mogła być glina pochodząca ze ścian, pieca oraz używanej ceramiki, szczątki kostne ludzkie i zwierzęce. Taki rozkład przestrzenny może wskazywać też na strefę o większej intensywności użytkowania, co potwierdza nagromadzenie występowania obiektów archeologicznych we wnętrzu chaty. Problem jest przedmiotem dalszych analiz specjalistycznych.
Tabela 2. Zawartość materii organicznej, węglanu wapnia i fosforu ogólnego w analizowanych osadach

Table 2. The content of organic matter, calcium carbonate and total phosphorus in the analyzed sediments

\begin{tabular}{lrcc}
\hline \multirow{2}{*}{ Parametr } & $\begin{array}{c}\text { Materia } \\
\text { organiczna }\end{array}$ & $\begin{array}{c}\text { Węglan } \\
\text { wapnia }\end{array}$ & $\begin{array}{c}\text { Fosfor } \\
\text { ogólny }\end{array}$ \\
\cline { 2 - 4 }$[\%]$ & \multicolumn{3}{c}{$\left[\mathrm{kg}^{-1}\right]$} \\
\hline Min. & 4,56 & 1,74 & 1200,0 \\
Średnia & 8,30 & 5,23 & 2650,7 \\
Maks. & 12,45 & 10,77 & 4340,0 \\
\hline
\end{tabular}

Uzyskane wyniki analiz zawartości fosforu pozwalają wyznaczyć strefy o największej intensywności aktywności ludzkiej na badanym obszarze (ryc. 10). Analiza przestrzennego rozkładu tego pierwiastka wykazuje wyraźny wzrost jego zawartości w części południowo-zachodniej badanego terenu. W części centralno-zachodniej, położonej poza udokumentowaną chatą, jego nagromadzenie jest największe (4000$4400 \mathrm{mg} \mathrm{kg}^{-1}$ ). We wnętrzu domostwa nie zaobserwowano tak wysokich wartości. Najwyższy udział tego pierwiastka występuje $\mathrm{w}$ miejscu rekonstruowanego wejścia do chaty. Można wnioskować, że strefy w najbliższym otoczeniu domu mogły być wykorzystywane w gospodarstwie domowym, np. do składowania lub wyrzucania odpadów, dokarmiania zwierząt itp. (Bednarek, Pokojska 1996, Bednarek 2007).

$\mathrm{Z}$ analizy macierzy korelacji pomiędzy oznaczonymi parametrami litologicznymi i geochemicznymi wynika, że wzrost udziału frakcji grubszych w osadzie powiązany jest $z$ lepszym wysortowaniem osadu, co oznacza, że istniał czynnik selekcjonujący materiał grubszy (np. spłukiwanie) (tab. 3). Swiadczą o tym również ujemne korelacje pomiędzy odchyleniem standardowym a skośnością i kurtozą. Ponadto stwierdzono dodatnią relację pomiędzy drobnieniem osadu a wzrostem zawartości węglanu wapnia. Utwory z obniżoną zawartością $\mathrm{CaCO}_{3}$ występują w zachodniej części wykopu w miejscu spodziewanej ścieżki lub obejścia.

Tabela 3. Macierz korelacji pomiędzy badanymi parametrami uziarnienia oraz wskaźnikami geochemicznymi

Table 3. The correlation matrix between studied grain-size composition indicies and geochemical indicators

\begin{tabular}{lrrrcrcc}
\hline & \multicolumn{1}{c}{$\mathrm{Mz}$} & \multicolumn{1}{c}{$S D$} & \multicolumn{1}{c}{$S_{k}$} & $K_{G}$ & $\mathrm{MO}$ & $\mathrm{CaCO}_{3}$ & $\mathrm{P}$ \\
\hline $\mathrm{Mz}$ & & & & & & & \\
$S D$ & 0,44 & & & & & & \\
$S_{k}$ & 0,18 & $-0,48$ & & & & & \\
$K_{G}$ & $-0,03$ & $-0,62$ & 0,33 & & & & \\
$\mathrm{MO}$ & 0,02 & 0,04 & $-0,06$ & 0,02 & & & \\
$\mathrm{CaCO}_{3}$ & 0,47 & $-0,13$ & 0,32 & 0,22 & $-0,19$ & & \\
$\mathrm{P}$ & $-0,06$ & 0,00 & $-0,53$ & 0,02 & 0,06 & $-0,08$ & \\
\hline
\end{tabular}

Macierz korelacji na poziomie istotności $\alpha=0,05$. Ciemnym tłem wyróżniono współczynniki korelacji istotne statystycznie. 


\section{Wnioski}

Przeprowadzone badania stanowiły podstawę interpretacji zróżnicowania cech litologicznych i geochemicznych osadów $z$ warstwy podhumusowej występującej na badanym wykopaliskowo obszarze stanowiska archeologicznego Kakucs-Turján. Wyniki analiz litologicznych wykazały zróżnicowanie przestrzenne podstawowych wskaźników uziarnienia. Jest ono efektem użytkowania badanej strefy, którą w głównej mierze zajmowała chata, oraz oddziaływania procesów podepozycyjnych, szczególnie spłukiwania. W strefie, w której rekonstruowano przebieg ciągu komunikacyjnego, odnotowano nieco wyższy udział domieszek piaszczystych, co może świadczyć o nanoszeniu grubszego materiału, a także wymywaniu drobnych frakcji przez spłukiwanie. Dodatkowo warto zaznaczyć brak zarejestrowanych obiektów archeologicznych w tej strefie, co potwierdzać może użytkowanie tej formy jako ścieżki lub obejścia domostwa.

Zwiększona zawartość materii organicznej oraz węglanu wapnia w części północnej wykopu może dowodzić intensywnego użytkowania gospodarczego obszaru, gdzie w kolejnych warstwach zlokalizowano piec. Największe nagromadzenie fosforu odnotowano na zewnątrz chaty, w pobliżu wejścia do domu, co może być wskaźnikiem zwiększonej aktywności gospodarczej w tym miejscu.

Całość wykonanych analiz teksturalnych i geochemicznych wykazuje zgodność rezultatów z interpretacjami obrazu wynikowego prospekcji magnetometrycznej na badanym wykopaliskowo fragmencie osady. Udało się potwierdzić antropogeniczny charakter anomalii interpretowanej jako chata, a ponadto obecność reliktów ścieżki lub obejścia wokół domostwa w zachodniej części badanego obszaru.

\section{Podziękowania}

Badania zostały sfinansowane $\mathrm{w}$ ramach realizacji projektu Narodowego Centrum Nauki pt. „Otwarte społeczności - zamknięte przestrzenie. Dynamika osadnictwa obronnego, gospodarki i powiązań ponadregionalnych społeczeństw środkowej epoki brązu W regionie Kakucs (Węgry)" (nr grantu 2012/05/B/HS3/03714). Analizy geochemiczne osadów wykonał prof. UP dr hab. W. Spychalski z Katedry Gleboznawstwa Uniwersytetu Przyrodniczego w Poznaniu, za co składamy mu podziękowanie. Autorzy składają też podziękowanie dwóm anonimowym recenzentom za cenne uwagi i komentarze do wcześniejszej wersji tego artykułu. Serdeczne podziękowania należą się również prof. UAM dr hab. Iwonie Hildebrandt-Radke oraz mgr. Jakubowi Niebieszczańskiemu za dyskusję merytoryczną wyników oraz pomoc w ich graficznym opracowaniu.

\section{Literatura}

Bednarek R., 2007. Znaczenie studiów paleopedologicznych w archeologii środowiskowej. W: M. Makohonienko, D. Makowiecki, Z. Kurnatowska (red.), Środowisko - Człowiek - Cywilizacja. Seria wydawnicza Stowarzyszenia Archeologii Środowiskowej. Studia interdyscyplinarne nad środowiskiem i kulturą w Polsce. Bogucki Wydawnictwo Naukowe, Poznań: 71-91.

Bednarek R., Pokojska U., 1996. Diagnostyczne znaczenie niektórych wskaźników chemicznych w badaniach paleopedologicznych. W: B. Manikowska (red.), Metody badań paleopedologicznych i wykorzystanie gleb kopalnych w paleopedologii. Uniwersytet Łódzki: 25-29.

Bóna I., Meller A.V., 1975. Die Mittlere Bronzezeit Ungarns und ihre Südöstlichen Beziehungen. Archaeologia Hungarica, Series Nova 49, Akadémiai Kiadó, Budapest.

Folk R.L., Ward W.C., 1957. Brazos River bar: a study in the significance of grain size parameters. Journal of Sedimentary Petrology 27: 3-26.

Heiri O., Lotter A.F., Gerry Lemcke G., 2001. Loss on ignition as a method for estimating organic and carbonate content in sediments: reproducibility and comparability of results. Journal of Paleolimnology 25: 101-110.

Jaeger M., 2016. Bronze Age Fortified Settlements in Central Europe (Studia nad Pradziejami Europy Środkowej/Studien zur Archäologie in Ostmitteleuropa 17). Wydawnictwo Nauka i Innowacje, Bonn-Poznań.

Jaeger M., Kulcsár G., 2013. Kakucs-Balla-Domb. A Case Study in the Absolute and Relative Chronology of the Vatya Culture. Acta Archaeologica Hungarica 64(2): 289-320.

Juśkiewicz W., 2006. Gradistat 5.11 beta, oprogramowanie komputerowe. Pakiet Analiz Statystycznych i Graficznej Prezentacji Rozkładu Uziarnienia Nieskonsolidowanych Osadów Mechanicznego Rozdziału na Sitach oraz Automatycznego Pomiaru Analizatorem Laserowym.

Kis E., 1995. Granulometric Investigations of Loess Profiles in Hungary. GeoJournal, Loess-Paleosol and Paleoclimatic Investigations: Principles, Methods and Criteria 36(2/3): 151-156.

Kocsis K., Schweitzer F., 2009. Hungary in maps. Geographical Research Institute Hungarian Academy of Sciences, Budapest.

Kuti L. (red.), 2005. Magyarország Földtani Térképsorozata, 1:100 000, arkusz: L-34-27, Dabas. Geological and Geophysical Institute of Hungary, Magyar Foldtani es Geofizikai Intezet.

Murphy J., Riley J.P., 1962. A modified single solution method for determination of phosphate in natural waters. Analytica Chimica Acta 27: 31-36.

Racinowski R., Szczypek T., Wach J., 2001. Prezentacja i interpretacja wyników badań uziarnienia osadów czwartorzędowych. Wydawnictwo Uniwersytetu Śląskiego, Katowice: 108.

Smalley I., Leach J., 1978. The origin and distribution of the loess in the Danube basin and associated regions of east-central Europe - a review. Sedimentary Geology 21: 1-26.

Spychalski W., Mocek A., Gilewska M., Owczarzak W., Otremba K., 2016. Możliwości rekultywacji i wykorzystania rolniczego gruntów pogórniczych na przykładzie doświadczenia prowadzonego na zwałowisku odkrywki węgla brunatnego Pątnów. Wydawnictwo Uniwersytetu Przyrodniczego, Poznań.

Szeverényi V., Kulcsár G., 2012. Middle Bronze Age Settlement and Society in Central Hungary. W: M. Jaeger, J. Czebreszuk, K.P. Fischl (red.), Enclosed Space-Open Society. Contact and exchange in the context of Bronze Age Defensive Settlements in Central Europe (Studia nad Pradziejami Europy Środkowej/ Studien zur Archäologie in Ostmitteleuropa 10). Bonn-Poznań: 287-351. 